\title{
Analysis of equality in Iranian household healthcare payments during Iran's fourth development program
}

Hamid Pourasghari ${ }^{1}$, Mehdi Jafari ${ }^{1,2}$, Mohammad Bakhtiari ${ }^{2,3}$, Iman Keliddar ${ }^{3}$, Afifeh Irani ${ }^{3,4}$, Mahnaz Afshari ${ }^{3,4}$

${ }^{1}$ Department of health Services Management, School of Health Management and Information Sciences, Iran University of Medical Sciences, Tehran, Iran

${ }^{2}$ Health Management and Economics Research Center, Iran University of Medical Sciences, Tehran, Iran

${ }^{3}$ Department of Health Management and Economics, School of Public Health, Tehran University of Medical Sciences, Tehran, Iran

${ }^{4}$ Research Center for Health Services Management, Institute for Future Studies in Health, Kerman University of Medical Sciences, Kerman, Iran

\section{Type of article: Original}

\begin{abstract}
Introduction: Today, the provision of healthcare should be efficient and equitable to achieve the health system's goals. The aim of this study was to survey equality in healthcare expenditures and its effects on income redistribution.

Methods: This study was a descriptive-analysis, cross-sectional study that was conducted with data obtained from the Statistical Center of Iran (SCI) during 2006 and 2011. The source population and study population were the urban and rural residents of Iran and their households' income and expenditures on health. The analysis was based on annually aggregated data from all provinces relative to their share of the total population. The data were collected using a pre-tested checklist consisting of two sections. The first section was used to retrieve data about total gross non-food expenditures of households. The second section retrieved out-of-pocket payments for healthcare. The data that were collected were analyzed using a Microsoft Excel spreadsheet. The Kakwani index was used to measure the extent of the deviation from equity. The redistributive effect of healthcare costs was considered as the impact of healthcare payments on households' income distribution.

Results: The overall Kakwani index during the fourth development program for urban households was progressive $(\mathrm{OKI}=0.013)$, but it was regressive for rural households $(\mathrm{OKI}=-0.012)$. Healthcare payments had a negative effect on income redistribution in urban areas during the entire period of the study, and they had a positive effect in rural areas, except for the years 2010 and 2011, for which the effects were negative and nonexistent, respectively.

Conclusion: By regarding the regressive Kakwani index and the negative effect of healthcare expenditures on income redistribution in some years, the government can use health grants, such as increasing health facilities and supplementary insurance, to increase the ability of households to deal with the cost of developing a remedy and reducing health inequalities.
\end{abstract}

Keywords: Kakwani index, Gini index, Development program, Healthcare, Households

\section{Introduction}

Health systems are established to perform the functions of financing (collecting, pooling, and purchasing) the delivery of health services, generating resources, and encouraging good stewardship. To achieve these goals, the provision of healthcare should be efficient and equitable (1). Decision-makers have been using the concepts of equity and justice in many different fields. The rapid increase in healthcare costs, especially those related to diagnostics and treatment, have been gaining more attention by health policy makers throughout the world (1). The existence of an unfair healthcare financing, including catastrophic payments, may lead to short-run poverty or sustained poverty (2). Thus, healthcare payments are among the issues that require more attention. Analyzing

\section{Corresponding author:}

Mehdi Jafari, Iran University of Medical Sciences, Tehran, Iran. Tel: +98.9123210131, Email: mjafari@iums.ac.ir Received: February 09, 2016, Accepted: May 03, 2016, Published: July 2016

iThenticate screening: May 03, 2016, English editing: May 17, 2016, Quality control: July 02, 2016

(C) 2016 The Authors. This is an open access article under the terms of the Creative Commons Attribution-NonCommercialNoDerivs License, which permits use and distribution in any medium, provided the original work is properly cited, the use is non-commercial and no modifications or adaptations are made. 
healthcare payments is a way of creating understanding about justice in healthcare financing among different population groups (3). The amount of money that people pay for healthcare may comprise a larger share of their income and may lead to catastrophic payments. This situation can force families to decrease the share of some of their essential means of living, such as their expenditures for food and clothes, or they may not be able afford the cost of education for their children (4). The undesirable effects of illness on the wage level and welfare of poor households may cause them to incur even greater poverty (5). Since part of a household's income must be related to health costs, the size of this share and its distribution always have been important. Thus, the share of a household's income paid for healthcare reflects the severity of the burden of healthcare costs on societies (6). Evidence has shown that healthcare expenditures in Iran have been increasing $(7,8)$. This could be related to the improvements in essential services or to the induced demand resulting from the uncontrolled use of expensive medical technologies. Accordingly, this issue requires the attention of policy-makers in redistributing and promoting equity in healthcare expenditures. This may be accomplished by proper health sector financing that ensures equality in healthcare payments by taking into account the income and wealth redistribution of people $(9,10)$. Therefore, the aim of this study was to survey equality in healthcare expenditures and its effects on income redistributions among urban and rural Iranian residents during Iran's fourth development program.

\section{Material and Methods}

A descriptive analysis was conducted on data obtained from the Statistical Center of Iran (SCI) during 2006-2011 The source population and study population were Iran's urban and rural residents' household incomes and their expenditures on healthcare. The analysis was based on annually aggregated data from all provinces relative to their share of the total population. In this study, households' costs were considered as a proxy for households' incomes. The data were collected using a pre-tested checklist that had two sections. The sections were meant to retrieve data about gross non-food expenditure of households, including expenditures on clothing, housing, furniture, transportation, entertainment and amusement, education, and healthcare. The gross data were used to minimize the possible bias that might have occurred during data collection from households. The second section of the checklist was used to retrieve out-of-pocket payments for healthcare, including the total cost of non-food expenditures. The collected data were entered into and analyzed using a Microsoft Excel spreadsheet. The Kakwani index, which ranges from -2 to 1 , was used to measure the extent of deviation from equity. Measures greater than zero indicated inequality favoring the rich and less than zero indicated inequality disadvantaging the poor. The redistributive effect of healthcare costs was considered as the impact of healthcare payments on households' income distribution. If the Gini index of healthcare payments was less than the Gini index of income, the redistributive impacts of the costs lead to equality in income distribution. The descriptive findings were presented graphically and in tables. Because the variances of operating costs were higher than income variance, the cost related data were more reliable than income-related data.

\section{Results}

In this study, we determined the average gross non-food expenditures, payments for healthcare, Gini index for each variable, Kakwani index, and redistributive effects of healthcare costs of households. As shown in Table 1, the Gini coefficient of gross non-food expenditures for urban households was at its maximum value (0.29) in 2006 and at its minimum value (0.26) in 2009 and 2010. However, the Gini coefficient of gross non-food expenditures for rural households was at its maximum (0.28) in 2011 and at its minimum (0.26) in 2006 and 2007.

Table 1. Average of non-food expenditure, annual payments for health care and their Gini index by residence among households in Iran (2006-2011)

\begin{tabular}{|l|l|l|l|l|l|l|l|l|}
\hline Year & \multicolumn{2}{l|}{$\begin{array}{l}\text { Gini index for } \\
\text { healthcare payments }\end{array}$} & \multicolumn{2}{l|}{$\begin{array}{l}\text { Gini index for non- } \\
\text { food expenditure }\end{array}$} & \multicolumn{2}{l|}{$\begin{array}{l}\text { Average of health care } \\
\text { payments }\end{array}$} & \multicolumn{2}{l|}{$\begin{array}{l}\text { Average of non-food } \\
\text { expenditure }\end{array}$} \\
\cline { 2 - 9 } & Rural & Urban & Rural & Urban & Rural & Urban & Rural & Urban \\
\hline 2006 & 0.24 & 0.3 & 0.26 & 0.29 & 23302147 & 34488343 & 238644164 & 449685837 \\
\hline 2007 & 0.23 & 0.29 & 0.26 & 0.28 & 34488343 & 35120471 & 265504567 & 506674993 \\
\hline 2008 & 0.24 & 0.31 & 0.27 & 0.28 & 28647768 & 46115723 & 302231543 & 604061054 \\
\hline 2009 & 0.22 & 0.3 & 0.27 & 0.27 & 36374750 & 59347546 & 343520491 & 756616708 \\
\hline 2010 & 0.32 & 0.29 & 0.27 & 0.27 & 11335824 & 63744743 & 385984854 & 799298092 \\
\hline 2011 & 0.22 & 0.3 & 0.27 & 0.28 & 51854495 & 78865582 & 78865582 & 902536134 \\
\hline
\end{tabular}


Also, the Gini coefficient of healthcare payments for urban households had a maximum value (0.31) in 2008 and a minimum value (0.29) in 2007 and 2010. Similarly, the Gini coefficient of healthcare payments for rural households was maximum (0.32) in 2010 and minimum (0.22) in 2009 and 2011. Healthcare payments had a negative effect on income redistribution in urban areas during the entire study period, with maximum effects in 2011 and minimum effects in 2007 (Table 2). In rural areas, the redistributive effect was positive in almost all of the years except 2010 and 2011, which had negative and no effects, respectively. The highest redistributive effect for rural households occurred in 2009. That is, the effect of healthcare payments on income distribution of the urban households in all the study years and in 2010 for rural households was worse. The income distribution for rural households was improved from 2006 to 2009, and it had no any effect on rural households' income distribution in 2011. Generally, variations in the redistributive pattern of healthcare payments for urban and rural households were observed (Figure 1). For the urban households, the pattern was initially higher in 2007, showing an increased income inequality due to healthcare payments, and then it decreased in 2008 and 2009, indicating a decreasing pattern of income inequality due to healthcare payments. However, in 2010, it increased again, after which it decreased to its lowest level. In rural households, the trend was a rising and falling pattern, with the highest and lowest levels of inequalities in 2009 and 2010, respectively. In 2011, healthcare payments didn't show any effect on household income distribution. The findings indicated that the payments were slightly progressive for the urban households in 2011, with rich households allocating a larger share of their income to healthcare payments relative to poor people (Table 3). However, the index was slightly regressive in the other years, suggesting that the poor households were allocating a larger share of their income to healthcare payments relative to the rich households; the 2009 Kakwani index $(-0.28)$ was more regressive than in the other years. In addition, the healthcare payment for rural households in 2010 was slightly regressive, while, for the remaining years, the Kakwani index was slightly progressive with the highest progressive index in $2011(0.054)$.

Table 2. Redistributive effects of health care payments on Iranian households base of urban and rural households (2006-2011)

\begin{tabular}{|l|l|l|l|l|}
\hline Year & \multicolumn{2}{|l|}{$\begin{array}{l}\text { Redistributive effects of healthcare } \\
\text { payments }\end{array}$} & $\begin{array}{l}\text { Average of gross non-food expenditure after deducting healthcare } \\
\text { payments }\end{array}$ \\
\cline { 2 - 5 } & Urban & Rural & Urban & Rural \\
\hline 2006 & -0.003 & 0.002 & 415197494 & 211184111 \\
\hline 2007 & -0.002 & 0.004 & 458454522 & 238622468 \\
\hline 2008 & -0.005 & 0.003 & 557945331 & 273583775 \\
\hline 2009 & -0.005 & 0.005 & 697269162 & 307145771 \\
\hline 2010 & -0.004 & -0.001 & 735553349 & 374649030 \\
\hline 2011 & -0.006 & 0 & 823670552 & 307145771 \\
\hline
\end{tabular}

Table 3. Kakwani index of Iranian households' health care payments during the fourth development program in urban and rural areas (2006-2011)

\begin{tabular}{|l|l|l|l|l|l|l|l|}
\hline \multirow{2}{*}{ Location } & \multicolumn{3}{|l|}{ Year } & \multicolumn{3}{|l|}{ Overall Kakwani index } \\
\cline { 2 - 8 } & 2006 & 2007 & 2008 & 2009 & 2010 & 2011 & \\
\hline Urban & -0.012 & -0.008 & -0.024 & -0.028 & -0.022 & 0.022 & -0.012 \\
\hline Rural & -0.028 & 0.03 & 0.027 & 0.045 & -0.05 & 0.054 & 0.013 \\
\hline
\end{tabular}

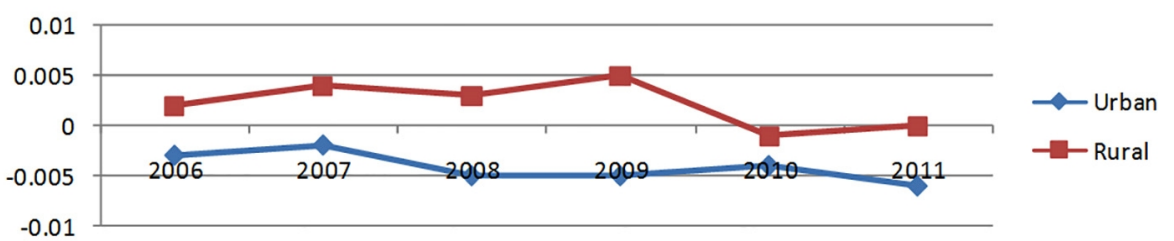

Figure 1. Redistributive effect of health care payment trend in urban and rural households (2006-2011)

The overall Kakwani index during the fourth development program for urban households was progressive (0.013). That is, the rich households allocated a larger share of their income to healthcare payments than poor households. The Kakwani index was regressive (-0.012) for the rural households (Figure 1). The overall trend of the Kakwani index for urban and rural people was progressive. For the urban households, initially, the index was higher in 2007, and it decreased in 2008 and 2009. In 2010, it increased again, reaching its highest level in the last year. For the 
rural households, there was not a significant variation in the Kakwani index up to 2008. However, in the remaining three years, there were increasing and decreasing trends, with the lowest and highest levels in 2010 and 2011, respectively (Figure 2).

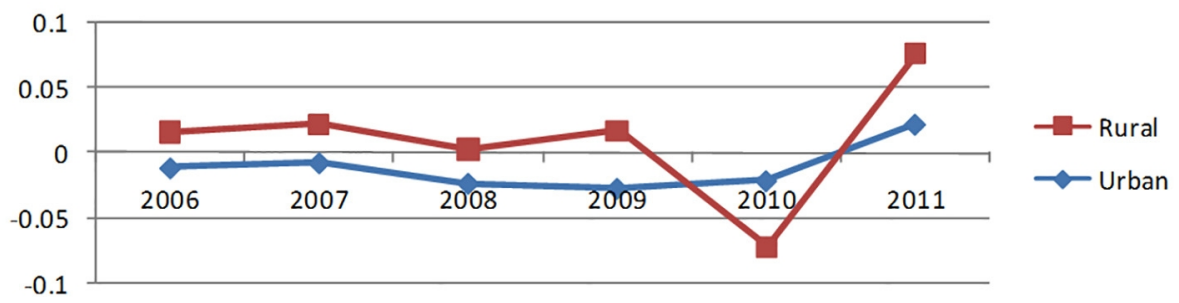

Figure 2. Trends of Kakwani index for Iranian households' health care payments during the fourth development program in urban and rural areas (2006-2011)

\section{Discussion}

The Kakwani index and redistributive effect of healthcare payments can used to assess equity in the health sector. In this study, the Kakwani index and the analysis of the redistributive effect of healthcare payments were conducted on urban and rural Iranian households using the budget data on households during the fourth development program of Iran (2005 to 2011). The findings on the redistributive effect of healthcare payments showed that the costs had different effects on the households' income distributions. There has been a positive effect on income distribution of the urban households in all of the study years, suggesting the presence of high overall inequality. Because rural households have relatively lower incomes than urban households, the possibility of catastrophic health payments in rural households (allocation of more than $40 \%$ of the households' income to healthcare) is much higher than in urban households. Thus, the possibility of becoming poor due to catastrophic health payments and difference in income distribution and increasing Gini coefficient will increase. The urban, middle-class households (Middle deciles) relative to other deciles had the lowest catastrophic health payments, and this led to declining household poverty due to healthcare payments, improving equity index, and decreasing Gini index. Hajizadeh investigated the redistributive effects of total direct costs, including healthcare payments and social insurance payments in 1996 and 2001, and his findings showed that these costs have positive effects on income redistribution in all years of the study periods and improved income distribution (11). However, rural households' healthcare payments in 2006 and 2009 had a negative effect on income distribution and led to decreased inequality, and, in 2010, this effect was positive and in the final year (2011) payments did not have any effect on household's income distribution, which may have been due to the lack of insurance development in rural areas. Mehr-Ara et al. examined inequality in healthcare expenditure financing in Iranian households in 2006. They concluded that inequality was higher in rural areas than in urban areas. Also, facing catastrophic health expenditures was significantly higher in rural areas than in urban areas (10.35\% and 6.5\%, respectively) (12). Examining equality in healthcare payments using the Kakwani index showed that this indicator did not show equality for rural and urban households so that for urban households this index was regressive and rich households paid a larger share of their income for healthcare payments, so inequality was greater among the poor in rural households, since this index was regressive, meaning that inequality is in favor of rich households. Vagei et al., in a comparative analysis of inequality in healthcare payments in different households in different provinces of Iran, concluded that healthcare payments were distributed unfairly between different provinces, so that the lowest and highest level of the Gini index between different provinces was 0.71 and 0.92 , respectively (1). Ghiasvand investigated healthcare utilization between different deciles of society in a 13 -year period and concluded that the average Kakwani indexes for healthcare payments in the study period for urban and rural households were -0.18 and -0.095 , respectively. This means that inequality is in favor of the poor (13). Shariary et al. examined the equity of healthcare payments in Gorgan Province and found that low income households spent about $40 \%$ of their income for healthcare, while rich households (tenth decile) spent 4.5 times more. This indicated a disparity in healthcare payments in favor of rich households (12). In a study conducted by the World Health Organization in eight countries that determined the equity in healthcare payments, it was found that direct out-of-pocket expenses varied greatly between the different deciles. The study showed that rich households in India and Tanzania pay a larger share of their income for healthcare expenditure (inequality in favor of the poor), while, in Mexico, Pakistan, and Brazil, poor households pay a larger share of their income as out-of-pocket expenses (inequality in favor of the rich). The highest inequality was seen in Vietnam, where prepayment expenditures in all deciles except for the tenth decile (rich households), which was near zero, and poor households paid a higher share of their income (almost $23 \%$ of their income) as out-of-pocket expenses (5). This study was limited to equity in 
healthcare expenditures, so the result should not be used for other social inequities; instead, related studies must be done.

\section{Conclusions}

In this study, we found that healthcare payments had a negative effect on income redistribution in urban areas and a positive effect in almost all of the years in rural areas. The overall Kakwani index for urban households was progressive and regressive for the rural households. So, the government can use health grants, such as supplementary insurance, to increase the ability of households to deal with the cost of healthcare and reduce health inequalities, thereby reducing the Gini coefficient. Increasing health facilities accounted for help with medical expenses also can reduce the equity gap further and increase equity. It will be useful in future research to study the relationship between insurance coverage rate and equity in health expenditures, or the role of supplementary insurance on increasing (or reducing) equity.

\section{Acknowledgments:}

This article is the result of a research project approved by the Iran University of Medical Sciences, Contract No. 9301-136-24390. We thank all of the people who helped us in conducting this research.

\section{Conflict of Interest:}

There is no conflict of interest to be declared.

Authors' contributions:

All authors contributed to this project and article equally. All authors read and approved the final manuscript.

\section{References:}

1) Waghei $\mathrm{Y}$, Niktinat S, Mohtashami Borzadaran Gh. Comparisonal study of inequality based on health expenses of households in Iran provinces. Journal of North Khorasan University of Medical Sciences. 2011; 3(Biostatistics and Epidemiology Supplement): 141-8.

2) WHO Fairness of financial contribution methodology. Geneva: WHO. 2002.

3) World Bank, USAID, WHO .Guide to producing national health account with special applications for lowincome and middle-income countries. 2003, Geneva: World Health Organization.

4) Ennett S, Gilson L, Mills A. Health economic development and household poverty: from understanding to action. 2008; Routledge.

5) WHO, World Health Report 2000: Health systems improving performance. WHO. 2000; 35-40.

6) $\mathrm{WHO}<$ Technical briefs for policy makers- Designing health financing systems to reduce health catastrophic health expenditure. WHO/HSF/PB/05, 02, 2005.

7) Hajimahmoodi H, Zahedi F. Justice in the healthcare system: payment and reimbursement policies in Iran. IJME. 2014; 6(3): 2-16.

8) Abolhallaje M, Mousavi SM, Jafari M. Implementation of Performance-Based Budgeting in the Health System: Luxury or Necessity? Iran J Public Health. 2014; 43(11): 1593-4. PMID: 26060733, PMCID: PMC4449515.

9) Murray Christopher JL, Knaulf, Musgrove p, Xu k, Kawabata K, Defining and Measuring Fairness in Financial Contribution to the health System. GPE Discussion paper series. 2000; 24: Eip/GPE/FAR. Geneva, World Health Organization. 5-6.

10) Jafari $M$, Bastani $P$, Ibrahimpour $H$, Dehnavieh $R$. Attitude of health information system managers and officials of the hspitals regarding the business producers: A qualitative study. Healthmed. 2012; 6(1): 20815.

11) Hajizadeh M. Ridistribution of Health Care Costs in Iran. Journal of Social Security. 2003; 5)14): 724-37.

12) Mehrara M, Fazaeli AA, Fazaeli AA. Health Finance Equity in Iran: an Analysis of Household Survey Data (1382-1386). Journal of Health Administration. 2010; 13(40).

13) Ghiasvand H. Syrvey Endowment of health services between different community decile. Reasearch Center of Majlis. 2014; 1-24.

14) Semnani SH, Keshtkar AA. Assessing of equality on health care cost in Gorgan population laboratory study. J Gorgan Uni Med Sci. 2003; 5(2): 53-9. 